\title{
Peter Kramer (1 November 1935-16 January 2009)
}

On the 16th January 2009 Peter Kramer died at the age of 73 of leukaemia.

Peter was one of the first Dutch paediatric radiologists. After finishing medical school in Amsterdam he moved to Maastricht for his training in radiology. In 1973 he accepted a position in the Wilhelmina Kinderziekenhuis in Utrecht. Those early years were not easy as the paediatricians had been used to interpreting radiological studies themselves. Peter established himself by quickly proving his expertise in radiology and he stayed in Utrecht until his retirement in 2000.

An important part of his job was teaching. He taught the secrets of paediatric radiology to many residents, not only from the University Medical Center Utrecht, but also from other teaching hospitals. He kept a large teaching file that is still in use because it contains a large number of easily accessible educational cases. For many years he organized the quarterly meeting of the Dutch Pediatric Radiologic Society, herding all the radiologists together as a true shepherd.

He was fond of his international friends and was a faithful attendee at the ESPR congresses. In 1994 he was elected President of the ESPR and organised the annual congress in Utrecht in 1995, the highlight of his career. In 2000 he was awarded honorary membership of the ESPR.

Peter loved working with children. When a resident was wrestling with an uncooperative child in the presence of upset parents, Peter only needed to walk into the room to turn the child into a meek lamb and to elevate the mood of the parents; a real doctor had arrived!

After his retirement he often dropped in to the department with a box of delicious sweets for a cup of coffee and a chat. At home he spent most of his time with

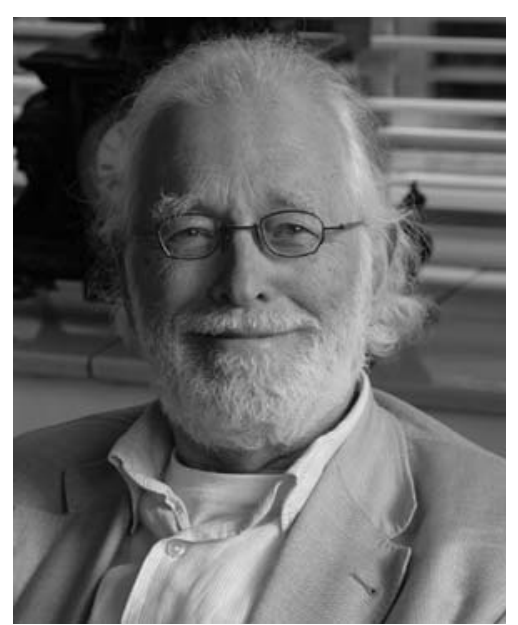

painting and sculpture and wrote a book on the spiritual side of life, focussing on Buddhism.

We will remember Peter as a kind and friendly man. A man with a beard, a shoulder bag, and a French hat; a man with a special eye for his co-workers, residents and technicians, with all their joys, sorrows and difficulties. Given the spirit and love for life that radiated from him, he died much too early. His motto was "enjoy life". He is survived by his children, Paul, Mariette and Bart, and eight grandchildren.

We thank him for all he accomplished for paediatric radiology in The Netherlands and even more for what he meant to us personally.

Rutger-Jan Nievelstein

Erik Beek 